\title{
Frequency of Anemia in the Patients of a Family Health Team in Dourados, Mato Grosso do Sul, Brazil
}

\author{
Tatiana Lachi' ${ }^{1}$ and Cássia Barbosa Reis ${ }^{2}$ \\ ${ }^{1}$ Universidade Federal da Grande Dourados, Rua João Rosa Goes no. 1761, Vila Progresso, Caixa Postal 322, \\ 79825-070 Dourados, MS, Brazil \\ ${ }^{2}$ Universidade Estadual de Mato Grosso do Sul, Cidade Universitária de Dourados, Caixa Postal 351, 79804-970 Dourados, MS, Brazil \\ Correspondence should be addressed to Tatiana Lachi, tlachi@yahoo.com
}

Received 17 April 2011; Revised 12 June 2011; Accepted 13 June 2011

Academic Editor: Aurelio Maggio

Copyright ( $\odot 2011$ T. Lachi and C. B. Reis. This is an open access article distributed under the Creative Commons Attribution License, which permits unrestricted use, distribution, and reproduction in any medium, provided the original work is properly cited.

\begin{abstract}
Anemia is a clinical manifestation with high prevalence in the world, reaching about $30 \%$ of the total inhabitants of the planet. It is responsible for a great reduction in quality of life of affected people. The present paper aimed to obtain the frequency of anemia in the blood counts of a sample from the population of registered patients of a Family Health Team in Dourados, MS, Brazil. 462 patients, who had blood counts done from February 2008 to March 2009, were included in this research. The frequency of anemia was $22.7 \%$ in the studied population, including all age groups.
\end{abstract}

\section{Introduction}

Anemia is a common finding in the world population, affecting both developing countries and industrialized nations. It reaches about 2 billion people worldwide, or about $30 \%$ of the total inhabitants of the planet, according to data from the World Health Organization-WHO. Because of such magnitude, it is considered a public health problem. It can greatly affect a person's life, especially in its more severe forms. Anemia causes tiredness, weakness, malaise, and making routine tasks more difficult and painful [1]. The affected person may be drowsy, with less resistance to physical activities and deterioration in cognitive function and immunity [2]. A drop in libido may occur [1]. Thus, quality of life can be seriously injured. Nutritional lack of iron leads to the most frequent type of anemia, iron deficiency anemia. Even motor development in children can be disturbed by iron deficiency [3-5], but this nutritional privation has easy and inexpensive care and prophylaxis. Thus, government or personal expenses to reverse its effects or avoid iron deficiency anemia are not large and can bring great improvements to the lives of individuals. In the staff's routine of the Family Health Strategy studied in Dourados, MS, Brazil, it can be seen that anemia affects a lot of patients. Therefore, a study about the frequency of that clinical manifestation can provide great information for the planning of prevention and treatment. The aim of this research was to obtain the frequency of anemia in blood counts of those patients.

\section{Methods}

A quantitative and descriptive study, with a retrospective component, using secondary data and blood counts from the medical records of patients subjected to research, was conducted in the city of Dourados, MS, Brazil. Patients ascribed to the Family Health Strategy studied totalize 4,244 people and a purposive sample of 462 patients from that population was used. The sample consists of patients who attended the Health Unit and had blood counts done during the period from February 2008 to March 2009. Pregnant patients were excluded. Data were collected through forms made by the author containing information on sex, age, and hematologic condition of the research subjects. Results were organized into charts and tables with descriptive statistical analysis through Software Excel 2007 and Epi-Info 3.3.2. This research was authorized by Committee of Stage, Practical Class, Research and/or Final Course Work from the Municipal Health Department-CEPET, and it was also 
approved by Ethics Committee on Human Research from Federal University of Mato Grosso do Sul-UFMS, according to Ordinance MS 196/96, protocol number 1497. Rules for use of information from patients' records are mentioned in items III.3.i and III.3.t of Resolution CNS 196/96 and they were followed. The present research did not entail risks to patients, since the blood samples had already been collected. It benefits population, since, from the determination of frequency of anemia, prevention and treatment actions can be made.

\section{Results}

3.1. General Frequency of Anemia. The frequency of anemia obtained in the studied sample was $22,7 \%$, including all age groups.

3.2. Frequency of Anemia by Age. The frequency of anemia by age in the studied sample is shown in Figure 1. Among the teenagers from 12 to 15 years old, $64.3 \%$ were anemic. Among children aged 1 year, this occurrence was $57.1 \%$, and in those aged $2-5$ years, it was $56 \%$. Anemia was found in $52.1 \%$ of children from 6 to 12 years. In children under 1 year in the sample, $30.8 \%$ were anemic, while $13.8 \%$ of people aged 16 years or more showed the same clinical manifestation at the time of collecting their blood counts. The oldest patient was 92 years old.

Tables 1 and 2 show the values of hemoglobin and the hematocrit found in the sample studied in relation to age range. Table 3 correlates the MCV (Mean Corpuscular Volume) values in relation to age range. Among children younger than 1 year, the most common hemoglobin values varied from 11.0 to $12.4 \mathrm{~g} / \mathrm{dL}$ (or $\mathrm{g} \%$ ), the range in which $53.8 \%$ of those patients were in (Table 1). The most frequent hematocrit values in the same patients were between 36 and $40.9 \%$, a range spanning $38.5 \%$ of those children (Table 2).

In patients aged from 1 to 15 years old and older than 15 years old, the most common hemoglobin values were between 12.5 and $13.9 \mathrm{~g} / \mathrm{dL}$, observed in $41.1 \%$ and $38.1 \%$ of those populations, respectively (Table 1), while their most frequent hematocrit ranged between 36 and $40.9 \%$, values found in $64.2 \%$ and $41 \%$ of those populations, respectively (Table 2). The hemoglobin and hematocrit found have meaning only if analyzed at the individual level, since they vary according to each age. Such analysis was subject of Figure 1.

Table 3 shows that the most frequent values of Mean Corpuscular Volume (MCV) among children under 1 year old varied from 80 to $84.9 \mu^{3}$, which are the values found in $46.2 \%$ of those patients, while both the population aged from 1 to 15 years old and aged over 15 years old showed most frequent MCV values between 85 and $89.9 \mu^{3}$. Those values were observed in $52.6 \%$ of patients aged from 1 to 15 years old and in $50.0 \%$ of patients over 15 years old.

The Mean Corpuscular Hemoglobin $(\mathrm{MCH})$ values in $61.6 \%$ of patients younger than 1 year old were between 25 and $28.9 \mathrm{ng}-30.8 \%$ of them with values between 25 and $26.9 \mathrm{ng}$ and other $30.8 \%$ with values between 27 and $28.9 \mathrm{ng}$. It was observed that $45.3 \%$ of patients aged from 1 to 15 years old had values of $\mathrm{MCH}$ between 27 and $28.9 \mathrm{ng}$, while $71.8 \%$ of patients over age 15 had MCH values between 29 and $30.9 \mathrm{ng}$ (Table 4).

Table 5 discriminates the values of Mean Corpuscular Hemoglobin Concentration (MCHC) that were found in each age. It is observed that in all age groups the most frequent $\mathrm{MCHC}$ values ranged from 32 to $33.9 \%$. Such values were found in $69.2 \%$ of patients younger than 1 year old, $83.2 \%$ of patients aged from 1 to 15 years old and $91.5 \%$ of patients over 15 years old.

Children under 1 year old have different reference values for hemoglobin, hematocrit, MCV, MCH, and MCHC, according to age. Figure 1 was constructed by analyzing each child individually. In tables, they were grouped into denomination "younger than 1 year old" to easy viewing.

Table 6 shows the reference values for each parameter (erythrocytes, hemoglobin, hematocrit, $\mathrm{MCV}, \mathrm{MCH}$, and $\mathrm{MCHC}$ ) according to age.

\section{Discussion}

The anemia frequency found in nearly $23 \%$ in population is high and it approaches those values found in the world: about $30 \%$ of its population were affected by anemia [6]. Such clinical manifestation can affect quality of life by decreasing exercise tolerance, impairing learning ability, affecting libido, causing fatigue, discomfort, and reducing appetite among other changes. Thus, over $20 \%$ of people who attended the Family Health Strategy team and who were included in this research face damage in their ability to perform daily activities, because of a blood disorder that can be easily avoided and also easily reversed once installed.

The presence of infectious processes in children and adolescents when blood counts were collected may have lead to a bias in the results, possibly overestimating frequency of real anemia, since a transient anemia can be found during an infectious process.

Anemias do not spare more affluent social classes. And the high number of anemia cases found in the study population proves what is observed throughout the country: anemias are the most prominent endemic deficiency, overcoming the lack of iodine (which is currently under control), vitamin $\mathrm{A}$, and even protein-calorie malnutrition [7].

After treatment in the population of our study, based on ferrous sulfate, it was possible to reverse most cases of anemia found. So iron deficiency anemia is supposed to be the most prevalent type of this clinical manifestation in those people. The values of Mean Corpuscular Volume, Mean Corpuscular Hemoglobin, and Mean Corpuscular Hemoglobin Concentration are needed if analyzed individually correlated with the values of hemoglobin $(\mathrm{Hb})$ and hematocrit $(\mathrm{Ht})$ for each patient studied and combined with additional laboratory tests, not available in records analyzed. Such analysis may be the object of further researches.

It can be seen in this study that the sample has prevalence of women: $62.6 \%$ of patients ( $95 \%$ CI 58.0 to 67.0 ). This is due to historical characterization that women are the majority of people who attend health services. 


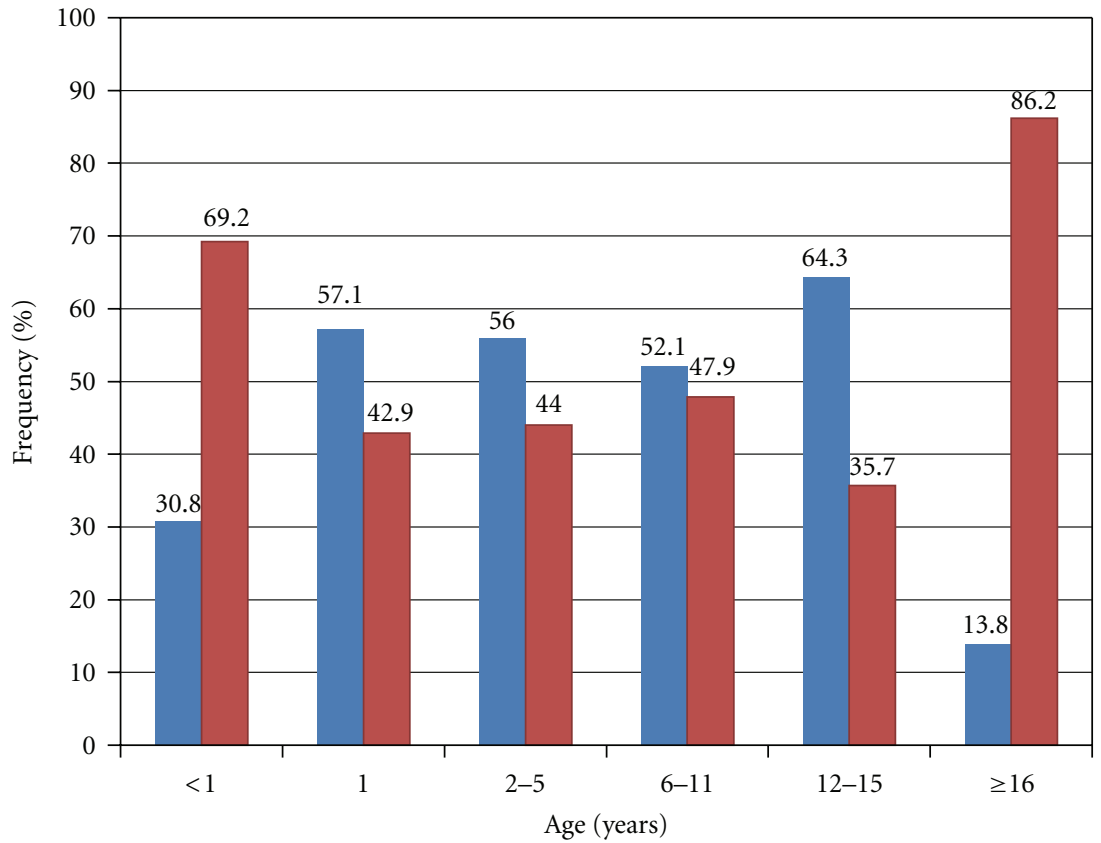

- With anemia

- Without anemia

FIGURE 1: Frequency of anemia in users of the Family Health Strategy studied, according to age range, from February 2008 to March 2009 , Dourados, MS, Brazil.

TABLE 1: Hemoglobin values according to age range, Dourados, MS, Brazil, 2009.

\begin{tabular}{|c|c|c|c|c|c|c|}
\hline \multirow{2}{*}{ Hemoglobin values (g/dL or $\mathrm{g} \%)^{*}$} & \multicolumn{2}{|c|}{ Younger than 1 year old } & \multicolumn{2}{|c|}{ From 1 to 15 years old } & \multicolumn{2}{|c|}{ Older than 15 years old } \\
\hline & $N$ & $\%$ & $N$ & $\%$ & $N$ & $\%$ \\
\hline $6.5-7.9$ & 1 & 7.7 & - & - & 1 & 0.3 \\
\hline $8.0-9.4$ & 2 & 15.4 & 2 & 2.1 & 2 & 0.6 \\
\hline $9.5-10.9$ & 3 & 23.1 & 14 & 14.7 & 12 & 3.4 \\
\hline $11.0-12.4$ & 7 & 53.8 & 36 & 37.9 & 63 & 17.8 \\
\hline $12.5-13.9$ & - & - & 39 & 41.1 & 135 & 38.1 \\
\hline $14.0-15.4$ & - & - & 3 & 3.2 & 115 & 32.5 \\
\hline $15.5-16.9$ & - & - & 1 & 1.1 & 24 & 6.8 \\
\hline $17.0-18.4$ & 一 & - & - & - & 2 & 0.6 \\
\hline Total & 13 & 100 & 95 & 100 & 354 & 100 \\
\hline
\end{tabular}

*g/dL: grams per deciliter of blood.

TABLE 2: Hematocrit values according to age range, Dourados, MS, Brazil, 2009.

\begin{tabular}{|c|c|c|c|c|c|c|}
\hline \multirow{2}{*}{ Hematocrit values (\%) } & \multicolumn{2}{|c|}{ Younger than 1 year old } & \multicolumn{2}{|c|}{ From 1 to 15 years old } & \multicolumn{2}{|c|}{ Older than 15 years old } \\
\hline & $N$ & $\%$ & $N$ & $\%$ & $N$ & $\%$ \\
\hline $21-25.9$ & 1 & 7.7 & - & - & 3 & 0.8 \\
\hline $26-30.9$ & 3 & 23.1 & 3 & 3.2 & 4 & 1.1 \\
\hline $31-35.9$ & 4 & 30.8 & 24 & 25.3 & 28 & 7.9 \\
\hline $36-40.9$ & 5 & 38.5 & 61 & 64.2 & 145 & 41.0 \\
\hline $41-45.9$ & - & - & 6 & 6.3 & 135 & 38.1 \\
\hline $46-50.9$ & - & - & - & - & 37 & 10.5 \\
\hline $51-55.9$ & - & - & 1 & 1.1 & 2 & 0.6 \\
\hline Total & 13 & 100 & 95 & 100 & 354 & 100 \\
\hline
\end{tabular}


TABLe 3: Mean Corpuscular Volume (MCV) values according to age range, Dourados/MS, Brazil, 2009.

\begin{tabular}{|c|c|c|c|c|c|c|}
\hline \multirow{2}{*}{ MCV values $\left(\mu^{3}\right)$} & \multicolumn{2}{|c|}{ Younger than 1 year old } & \multicolumn{2}{|c|}{ From 1 to 15 years old } & \multicolumn{2}{|c|}{ Older than 15 years old } \\
\hline & $N$ & $\%$ & $N$ & $\%$ & $N$ & $\%$ \\
\hline $50-55$ & - & - & - & - & 1 & 0.3 \\
\hline $55-60$ & - & - & - & - & - & - \\
\hline $60-65$ & 1 & 7.7 & 1 & 1.1 & 1 & 0.3 \\
\hline $65-70$ & - & - & 1 & 1.1 & 3 & 0.8 \\
\hline $70-75$ & 3 & 23.1 & 4 & 4.2 & 1 & 0.3 \\
\hline $75-80$ & 2 & 15.4 & 11 & 11.6 & 2 & 0.6 \\
\hline $80-85$ & 6 & 46.2 & 17 & 17.9 & 18 & 5.1 \\
\hline 85-90 & - & - & 50 & 52.6 & 177 & 50.0 \\
\hline 90-95 & 1 & 7.7 & 11 & 11.6 & 149 & 42.1 \\
\hline $95-100$ & 一 & 一 & - & - & 2 & 0.6 \\
\hline Total & 13 & 100 & 95 & 100 & 354 & 100 \\
\hline
\end{tabular}

TABle 4: Mean Corpuscular Hemoglobin (MCH) values according to age range, Dourados/MS, Brazil, 2009.

\begin{tabular}{|c|c|c|c|c|c|c|}
\hline \multirow{2}{*}{ MCH Values (ng) } & \multicolumn{2}{|c|}{ Younger than 1 year old } & \multicolumn{2}{|c|}{ From 1 to 15 years old } & \multicolumn{2}{|c|}{ Older than 15 years old } \\
\hline & $N$ & $\%$ & $N$ & $\%$ & $N$ & $\%$ \\
\hline $15-16.9$ & - & - & 1 & 1.1 & 1 & 0.3 \\
\hline $17-18.9$ & - & - & - & - & - & - \\
\hline 19-20.9 & 1 & 7.7 & - & - & 1 & 0.3 \\
\hline $21-22.9$ & 1 & 7.7 & 3 & 3.2 & 3 & 0.8 \\
\hline $23-24.9$ & 3 & 23.1 & 3 & 3.2 & 1 & 0.3 \\
\hline $25-26.9$ & 4 & 30.8 & 14 & 14.7 & 5 & 1.4 \\
\hline $27-28.9$ & 4 & 30.8 & 43 & 45.3 & 65 & 18.4 \\
\hline 29-30.9 & - & - & 30 & 31.6 & 254 & 71.8 \\
\hline $31-32.9$ & - & - & 1 & 1.1 & 21 & 5.9 \\
\hline $33-34.9$ & - & - & 一 & - & 3 & 0.8 \\
\hline Total & 13 & 100 & 95 & 100 & 354 & 100 \\
\hline
\end{tabular}

The values of hemoglobin and hematocrit found in patients with anemia in the study population characterize that clinical manifestation as mild in most cases and in all ages. There were few cases of moderate to severe anemia, which responded promptly to therapy with oral or parenteral replacement of iron, being characterized, although the lack of additional laboratory tests available, as iron deficiency anemia, because of its rapid response to treatment. The WHO defines mild, moderate, and severe anemia according to hemoglobin values. Mild anemia is characterized by hemoglobin values between 11.0 and $11.9 \mathrm{mg} / \mathrm{dL}$ in children and adult women and between 12 and $12.9 \mathrm{mg} / \mathrm{dL}$ in adult men. Moderate anemia occurs when hemoglobin values vary from 8.0 to 10.9 in children and adult women, and from 9.0 to 11.9 in adult men, and severe anemia has hemoglobin values from 5.0 to 7.9 in children and adult women and from 6.0 to 8.9 in adult men.

The findings of the present research are similar to those observed throughout Brazil, where anemia reaches about $50 \%$ of children between 6 months and 2 years old [6] and between 40 and $50 \%$ of children under 5 years old [7].

The iron fortification in widely consumed foods in each population was sustained as a measure of greater scope to try reducing such a high prevalence of anemia. Several studies show that food fortification can reduce nutritional deficiencies [8]. The supply of iron supplementation for the most vulnerable population groups (such as children, women at reproductive age, and pregnant women), food fortification, educational measures, and information to the population are strategies for combating anemia. If added together, they can be effective in fighting this serious public health problem all over the world [7].

\section{Conclusions}

The high frequency of anemia in the study population follows what can be seen worldwide. This clinical manifestation does not discriminate between rich or poor countries and affects a great number of people in several nations. A person's life can be greatly disturbed by its symptoms, such as tiredness, lower immunity, impairment in the growth of children, in cognitive functions, and libido [1, 2]. Lack of iron is a very common nutritional deficiency and it is responsible for the most frequent type of anemia in the world, the iron deficiency anemia [5]. The treatment in those cases is simple and inexpensive, and so is its prevention. 
TABLE 5: Mean Corpuscular Hemoglobin Concentration (MCHC) values according to age range, Dourados, MS, 2009.

\begin{tabular}{|c|c|c|c|c|c|c|}
\hline \multirow{2}{*}{ MCHC values (\%) } & \multicolumn{2}{|c|}{ Younger than 1 year old } & \multicolumn{2}{|c|}{ From 1 to 15 years old } & \multicolumn{2}{|c|}{ Older than 15 years old } \\
\hline & $N$ & $\%$ & $N$ & $\%$ & $N$ & $\%$ \\
\hline $26-27.9$ & - & - & 1 & 1.1 & 1 & 0.3 \\
\hline $28-29.9$ & - & - & - & - & 2 & 0.6 \\
\hline $30-31.9$ & 3 & 23.1 & 7 & 7.4 & 9 & 2.5 \\
\hline $32-33.9$ & 9 & 69.2 & 79 & 83.2 & 324 & 91.5 \\
\hline $34-35.9$ & 1 & 7.7 & 8 & 8.4 & 17 & 4.8 \\
\hline $36-37.9$ & - & 一 & - & 一 & 1 & 0.3 \\
\hline Total & 13 & 100 & 95 & 100 & 354 & 100 \\
\hline
\end{tabular}

TABLE 6: Reference values for erythrocytes, hemoglobin, hematocrit, MCV, MCH, and MCHC according to age. Source: Clinical Laboratory, University Hospital of Dourados, MS, Brazil. Brazilian Association of Hematology and Hemotherapy-(ABHH).

\begin{tabular}{|c|c|c|c|c|c|}
\hline Age & Hemoglobin (g/dL) & Hematocrit (\%) & $\operatorname{MCV}\left(u^{3}\right)$ & $\mathrm{MCH}$ (ng) & $\mathrm{MCHC}(\%)$ \\
\hline 5 days & $19-20$ & $60-65$ & $92-99$ & $30-40$ & $32-36$ \\
\hline 14 days & $12.5-15.7$ & $42-48$ & $60-70$ & $25-30$ & $27-34$ \\
\hline 2 months & $14-19$ & $40-50$ & $90-97$ & $28-33$ & $31-34$ \\
\hline 6 months & $9.5-13.5$ & $29-41$ & $74-99$ & $25-35$ & $30-36$ \\
\hline 12 months & $11.8-12.6$ & $35-40$ & $75-80$ & $25-30$ & $33-37$ \\
\hline 4 years & $12.3-13.8$ & $35-40$ & $75-80$ & $28-30$ & $33-37$ \\
\hline 8 years & $12.3-14$ & $38-42$ & $75-85$ & $28-30$ & $33-37$ \\
\hline 14 years & $13.5-14.5$ & $40-50$ & $82-92$ & $28-30$ & $32-36$ \\
\hline Adult men & $14-16$ & $40-54$ & $82-92$ & $27-32$ & $32-36$ \\
\hline Adult women & $11-14$ & $37-47$ & $82-92$ & $27-32$ & $32-36$ \\
\hline
\end{tabular}

Avoiding or treating anemia can contribute to a higher quality of life for people.

\section{References}

[1] J. C. Bennett and F. Plum, Eds., Cecil-Tratado de Medicina Interna, Guanabara Koogan, Rio de Janeiro, Brazil, 20th edition, 1997.

[2] G. G. P. Leme Coutinho, E. M. Goloni-Bertollo, and E. C. Pavarino-Bertelli, "Effectiveness of two programs of intermittent ferrous supplementation for treating iron-deficiency anemia in infants: randomized clinical trial," Sao Paulo Medical Journal, vol. 126, no. 6, pp. 314-318, 2008.

[3] B. Lozoff, "Early iron deficiency has brain and behavior effects consistent with dopaminergic dysfunction," The Journal of Nutrition, vol. 141, no. 4, pp. 740S-746S, 2011.

[4] L. A. Kazal Jr., "Prevention of iron deficiency in infants and toddlers," American Family Physician, vol. 66, no. 7, pp. 12171227, 2002.

[5] L.M. Tierney Jr., S. J. McPhee, and M. A. Papadakis, Eds., Diagnóstico e tratamento, Atheneu, São Paulo, Brazil, 2001.

[6] R. M. Neves, "Interações nutricionais na anemia ferropriva," Revista Nutrição, Saúde e Performance, vol. 6, no. 27, pp. 32-38, 2005.

[7] M. Batista Filho, "O controle das anemias no Brasil," Revista Brasileira de Saúde Materno Infantil, vol. 4, no. 2, 2004.

[8] C. Best, N. Neufingerl, J. M. Del Rosso, C. Transler, T. van den Briel, and S. Osendarp, "Can multi-micronutrient food fortification improve the micronutrient status, growth, health, and cognition of schoolchildren? A systematic review," Nutrition Reviews, vol. 69, no. 4, pp. 186-204, 2011. 


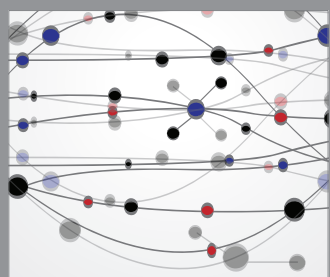

The Scientific World Journal
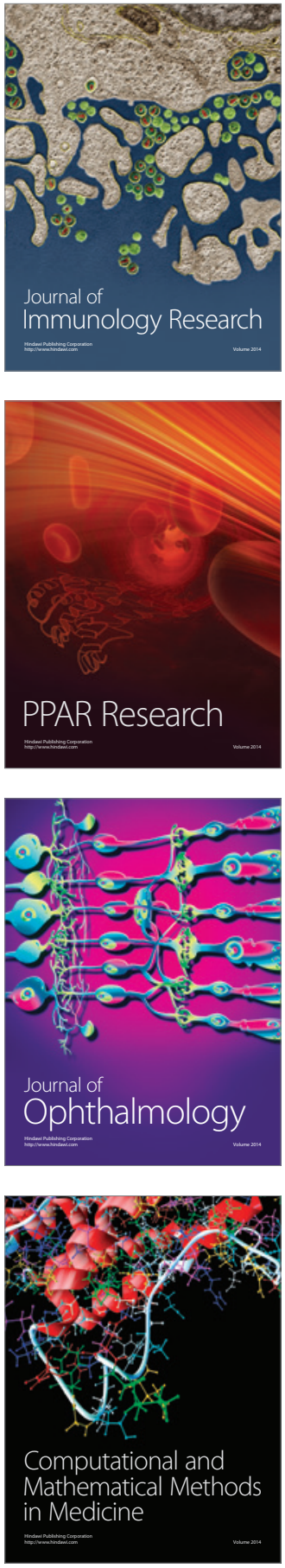

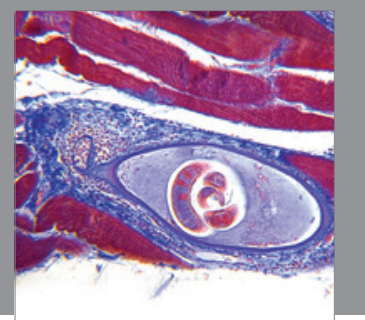

Gastroenterology

Research and Practice
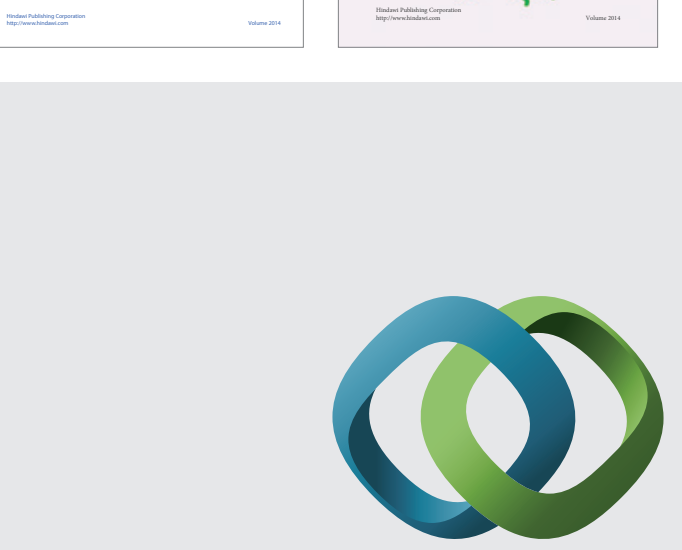

\section{Hindawi}

Submit your manuscripts at

http://www.hindawi.com
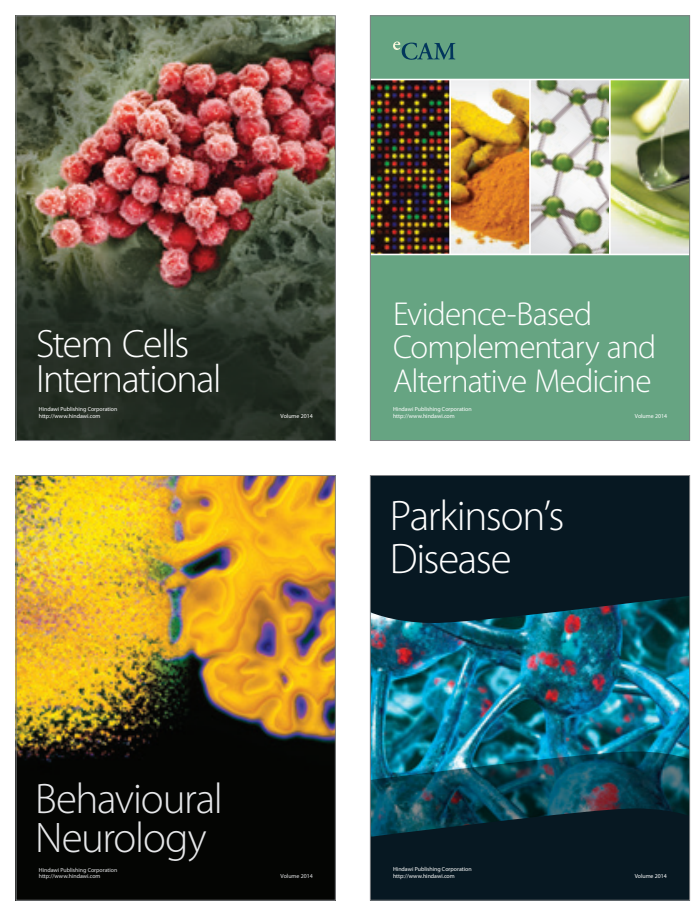

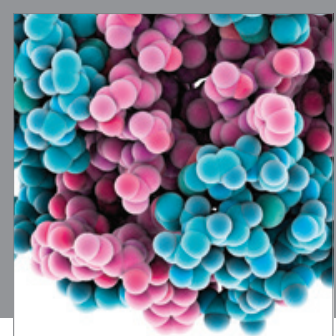

Journal of
Diabetes Research

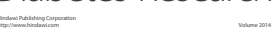

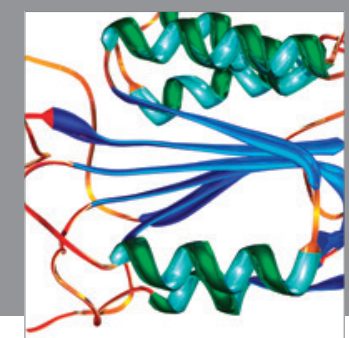

Disease Markers
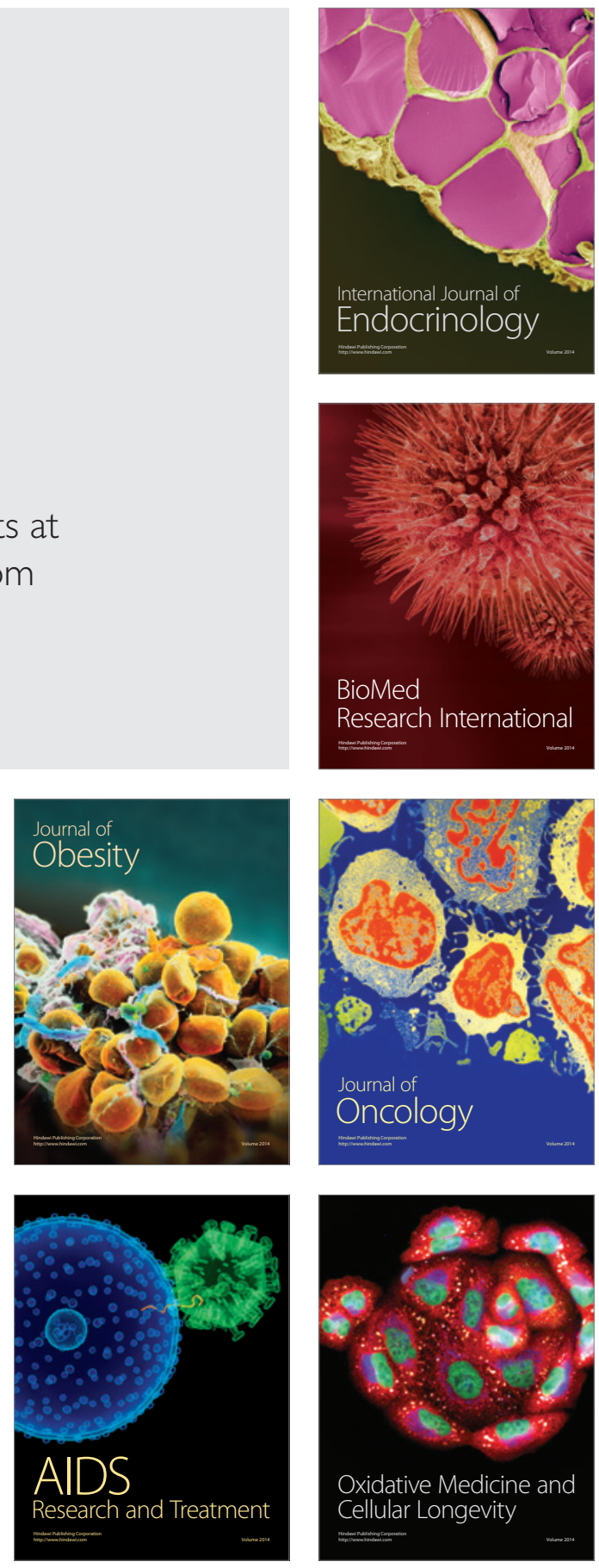